\title{
KEGIATAN PUBLIC RELATIONS SEBAGAI UPAYA PENGUATAN EKSISTENSI PERPUSTAKAAN
}

\author{
Neneng Komariah ${ }^{1 *}$, Saleha Rodiah ${ }^{2}$, M. Zaky Rakhmat ${ }^{3}$ \\ 1,2,3 Prodi Ilmu Perpustakaan Universitas Padjadjaran \\ *Korespondensi: neneng.komariah@unpad.ac.id
}

Diajukan: 17-08-2018; Direview: 10-09-2018; Diterima: 03-11-2018; Direvisi: 07-11-2018

\begin{abstract}
Library is an institution which provides selected information sources and services for people. The information sources available in library are selected and provided systematically makes people easy to find the needed information. However, some libraries suffer of lack of user so must be done library management for existance empowerment. This paper discuss implementation of "pencils" of public relations, it is a strategy in library empowerment conducted in Telkom University Open Library. Pencils of public relations is a strategy based on creating good relationship with relevant stakeholders which consists of publications, events, news, community involvement, identity tools, lobbying, and social investment. The research method used is descriptive qualitative and data collected by interview and focus group discussion. The results shows that the Telkom University Open Library has implemented "pencils" of public relations in strengthening its existence.
\end{abstract}

\begin{abstract}
ABSTRAK
Perpustakaan merupakan lembaga yang menyediakan sumber-sumber informasi yang sudah terseleksi dan disajikan secara sistematis sehingga memudahkan para pencari informasi untuk mendapatkan informasi yang dibutuhkan. Namun, banyak perpustakaan yang sepi pengunjung sehingga harus dilakukan manajemen perpustakaan untuk menguatkan eksistensinya. Tujuan penelitian ini adalah untuk mengkaji bagaimana implementasi strategi "pencils" of public relations, yaitu suatu strategi membina hubungan baik dengan stakeholders yang relevan dengan melakukan kegiatan publications, events, news, community involvement, identity tools, lobbying, social investment. Pencils sebagai upaya penguatan perpustakaan di Telkom University Open Library. Metode yang digunakan adalah kualitatif dengan teknik pengumpulan data wawancara, focus group discussion, dan studi pustaka. Hasil penelitian menunjukkan bahwa Telkom University Open Library telah mengimplementasikan strategi "pencils" of public relations sebagai usaha penguatan eksistensinya.
\end{abstract}

Keywords: Public relations; Communication; Promotion; Library services; Academic library; Telkom University

\section{PENDAHULUAN}

Menteri Pendidikan dan Kebudayaan RI (Anies Baswedan) mengatakan bahwa "perpustakaan sebagai infrastruktur penunjang kebiasaan membaca di Indonesia kondisinya lebih baik jika dibandingkan dengan Jerman, Korea Selatan, Selandia Baru, dan negara lain di Eropa-namun menurut hasil penelitian Central Connecticut State University tahun 2016, tingkat literasi masyarakat Indonesia masih sangat menyedihkan-Indonesia berada di posisi ke-60 dari 61 negara" (Koran Sindo, 2016). Hal tersebut menunjukkan bahwa Berita tersebut menggambarkan bahwa minat baca masyarakat Indonesia masih rendah. Minat baca masyarakat yang rendah tentunya akan merugikan perpustakaan sebagai institusi yang menyediakan sumber-sumber informasi atau bahan pustaka untuk dimanfaatkan atau dibaca oleh masyarakat. Investasi yang telah dilakukan untuk pembangunan gedung, pembelian koleksi, rekrutmen dan pelatihan staf perpustakaan akan menjadi sia-sia jika masyarakat tidak datang memanfaatkan layanan yang telah disediakan perpustakaan. 
Masyarakat memandang bahwa pembangunan infrastruktur perpustakaan umum di beberapa daerah sudah relatif baik, namun masih banyak dari mereka yang belum mengetahui dan menyadari arti pentingnya perpustakaan bagi kehidupan sosial. Mereka masih memandang perpustakaan hanya diperlukan oleh anak sekolah atau mereka yang sedang belajar. Para pedagang yang berjualan di pasar, para pengemudi angkutan umum, bahkan para karyawan di berbagai institusi pemerintahan masih belum akrab dengan perpustakaan. Keadaan tersebut harus menjadi perhatian dan fokus pemikiran para pengelola perpustakaan. Perpustakaan harus melakukan berbagai kegiatan yang bersifat membuka dan mendekatkan diri pada masyarakat. Hal tersebut dilakukan agar mereka mengetahui dan memahami fungsi perpustakaan, serta tertarik untuk mengunjungi dan memanfaatkan berbagai sumber informasi perpustakaan.

Selama ini banyak perpustakaan yang telah melakukan kegiatan promosi untuk memperkenalkan diri pada masyarakat. Namun, masih banyak kegiatan promosi yang dilaksanakan perpustakaan hanya sekali dengan media promosi yang sederhana sehingga tidak sesuai dengan selera masyarakat. Banyak perpustakaan yang belum memiliki program promosi yang terintegrasi dan terencana dengan baik. Perpustakaan seharusnya menyelenggarakan kegiatan promosi untuk lebih menguatkan keberadaannya, serta melakukannya berdasarkan kaidah-kaidah ilmu pemasaran.

Telkom University merupakan salah satu perguruan tinggi swasta yang ada di Kabupaten Bandung, Jawa Barat. Perguruan tinggi swasta ini memiliki perpustakaan yang diberi nama Telkom University Open Library. Nama open library mengandung makna bahwa perpustakaan ini telah menganut open access, yang berarti bahwa perpustakaan terbuka untuk siapa saja yang ingin memanfaatkan sumber daya informasinya. Perpustakaan ini menyediakan perpustakaan digital dan layanannya dapat diakses melalui internet, sehingga pengguna tidak perlu lagi datang ke perpustakaan untuk mengakses sumber-sumber informasi yang diperlukan.

Meskipun telah menerapkan sistem open access, Telkom University Open Library harus berupaya keras untuk menarik penggunanya agar senantiasa memanfaatkan layanan yang disediakan. Upaya tersebut dapat berupa kegiatan, seperti membuat berbagai publikasi, menyelenggarakan berbagai event, dan melibatkan diri dalam berbagai kegiatan sosial. Hal tersebut perlu dilakukan karena Telkom University telah melakukan investasi yang besar untuk membangun sarana dan prasarana perpustakaan untuk pemenuhan kebutuhan informasi penggunanya.

Terkait dengan promosi dan pemasaran layanan perpustakaan, ada model atau paradigma yang dapat menjadi acuan, yaitu "pencils" of public relations. Menurut Kotler (1989), pencils merupakan kegiatan kehumasan (public relations) yang terdiri dari kegiatan publications, events, news, community involvement, identity tools, lobbying, dan social investment. Paradigma ini menurut Harris (1991) disebut juga sebagai public relations mix. Semua kegiatan dilaksanakan secara terpadu sebagai kegiatan public relations yang mendukung kegiatan pemasaran. Berdasarkan hal di atas, penelitian ini mengkaji tentang: bagaimana kegiatan public relations yang terdiri dari publications, events, news, community involvement, identity tools, lobbying, social investment dilaksanakan oleh Telkom University Open Library?. 


\section{TINJAUAN PUSTAKA}

\subsection{Public Relations}

Salah satu kegiatan pemasaran adalah hubungan masyarakat (public relations). Griswold mengatakan bahwa "public relations is the management function which evaluates public attitudes, identifies the policies and procedures of an individual or an organization with the public interest and plans and executes a program of action to earn public understanding and acceptance" (Wilcox, et al., 2000). Definisi tersebut bermakna bahwa fungsi manajemen itu mengevaluasi sikap publik, memperkenalkan berbagai kebijakan dan prosedur dari suatu individu atau organisasi berdasarkan kepentingan publik, membuat perencanaan, dan melaksanakan suatu program kerja dalam upaya memperoleh pengertian dan pengakuan publik.

Public relations idealnya terdiri dari berbagai kegiatan yang dilaksanakan secara terintegrasi dan proporsional sesuai dengan kebutuhan institusi yang menyelenggarakannya. Harris (1991) menjelaskan bahwa secara konsep berbagai kegiatan tersebut disebut sebagai public relations mix atau "pencils" of public relations. Kegiatan yang termasuk "pencils" of public relations, antara lain:

1) publications (publikasi), yaitu menyebarluaskan informasi melalui berbagai media tentang aktivitas lembaga yang layak diketahui publik serta dapat menghasilkan tanggapan yang positif dari masyarakat;

2) event (penyelenggaraan acara), yaitu menyelenggarakan acara yang dipilih dalam waktu, tempat, dan objek tertentu dengan tujuan untuk mempengaruhi opini public;

3) news (menciptakan berita), yaitu menulis berita berupa press release, berita yang dimuat dalam news letter atau bulletin;

4) community involvement (keterlibatan dalam masyarakat), yaitu melakukan kegiatan atau komunikasi dengan kelompok masyarakat tertentu di luar lembaga dengan tujuan untuk membina hubungan baik;

5) identity tools, yaitu berbagai alat atau perlengkapan yang menunjukkan identitas lembaga, misalnya logo, tag line, baju seragam pegawai, bentuk gedung, dsb.;

6) lobbying and negotiation, yaitu melakukan pendekatan secara pribadi dan bernegosiasi untuk membicarakan hal-hal penting dengan pihak tertentu untuk mencapai kesepakatan atau memperoleh dukungan, sehingga timbul situasi yang saling menguntungkan;

7) social investment (tanggung jawab sosial), yaitu kemampuan lembaga dalam memberikan kontribusi sosial kepada masyarakat sebagai bentuk pertanggung-jawaban social, hal ini sering disebut sebagai corporate social responsibility (CSR).

\subsection{Public Relations di Perpustakaan}

Public relations merupakan konsep yang sesuai untuk diimplementasikan dalam usaha penguatan eksistensi perpustakaan terutama di era open access; di mana para pencari informasi dapat memperoleh informasi yang dibutuhkannya secara cepat dan mudah melalui gadget dan internet. Saez (2002) mengatakan bahwa "the communication method that libraries and information centres will use as the major tool in their promotional mix will almost certainly be public relations", yang berarti bahwa perpustakaan harus melaksanakan public relations untuk kegiatan promosi lembaganya. Usherwood (1981) menjelaskan bahwa tujuan kegiatan public relations di perpustakaan, antara lain sebagai berikut.

a) Achieving resources for library, perpustakaan mendapatkan sumber daya yang dibutuhkan seperti dana, fasilitas, sarana dan prasarana, dan staf yang berkualitas. 
Kegiatan public relations, seperti lobbying dapat mengubah opini publik yang negatif terhadap perpustakaan.

b) Public image of library, selama ini masyarakat masih berpikiran negatif dan belum menyadari peran penting dari perpustakaan. Kegiatan public relations ini diharapkan dapat meningkatkan citra positif perpustakaan.

c) Internal public relations, melalui kegiatan public relations diharapkan dapat meningkatkan rasa percaya diri staf perpustakaan dan pustakawan - ia adalah seorang yang cerdas dan mampu membantu masyarakat dalam mendapatkan sumber-sumber informasi yang butuhkan.

Dalam merencanakan kegiatan public relations, perpustakaan dapat mengadopsi public relations mix atau "pencils" of public relations. Kegiatan-kegiatan membuat publikasi, menyelenggarakan event, membuat berita, melibatkan diri dalam aktivitas sosial masyarakat sekitar, memiliki media sebagai identitas diri, melakukan lobbying dan negosiasi, dan melaksanakan social investment, merupakan kegiatan-kegiatan yang harus sudah dipikirkan dan dilaksanakan oleh perpustakaan, dan pelaksanaannya secara terintegrasi dan saling mendukung satu sama lain.

Komariah \& Rodiah (2017) menjelaskan tiga hal yang menjadi pertimbangan dalam mengimplementasikan kegiatan "pencils" of public relations, yaitu: (a) jenis perpustakaan, setiap jenis perpustakaan memiliki pengguna yang target layanannya berbeda, sehingga akan membutuhkan pendekatan komunikasi yang berbeda; (b) sumber daya perpustakaan, meliputi sumber daya yang berupa fasilitas, dana, dan sumber daya manusia/staf; dan (c) dukungan dari lembaga penaung, karena perpustakaan merupakan unit kerja yang ada di bawah lembaga induk. Perpustakaan merupakan bagian integral dari struktur sosial, yang secara khas membidangi pengelolaan informasi, dan hampir di semua lembaga atau organisasi sosial di masyarakat selalu ada perpustakaan (Yusup, 2009).

Perpustakaan perguruan tinggi merupakan perpustakaan yang ada di perguruan tinggi, badan bawahannya, maupun lembaga yang berafiliasi dengan perguruan tinggi, dengan tujuan utama membantu perguruan tinggi mencapai tujuannya, yakni tri dharma perguruan tinggi (pendidikan, penelitian, dan pengabdian masyarakat). Adapun fungsi perpustakaan perguruan tinggi, yaitu sebagai sarana simpan karya manusia, fungsi informasi, fungsi rekreasi, fungsi pendidikan, fungsi kultural (Sulistyo-Basuki, 1991)..

\section{METODE}

Metode penelitian yang digunakan adalah kualitatif dengan pendekatan studi kasus. Teknik pengumpulan data dilakukan melalui wawancara, focus group discussion, dan studi pustaka. Adapun tujuan penelitian adalah untuk mengetahui pembuatan publikasi, penyelenggaraan events, penerbitan news, melakukan community involvement, pembuatan identitas perpustakaan, kegiatan lobbying, dan kegiatan social investment di Telkom University Open Library.

\section{HASIL DAN PEMBAHASAN}

"Pencils" of public relations terdiri dari serangkaian aktivitas public relations yang dilaksanakan secara sinergi dalam rangka mencapai tujuan yang telah ditetapkan. Berdasarkan hasil wawancara dan observasi lapangan, Telkom University Open Library telah melaksanakan berbagai kegiatan yang terkait dengan "pencils" of public relations, diantaranya sebagai berikut. 


\section{Pembuatan Publikasi}

Telkom University Open Library sangat mengutamakan media publikasi online. Perpustakaan ini memiliki video, mailing list, website, dan media sosial line, instagram, dan facebook. Semua media dikelola secara profesional sebagai hasil kerjasama antara staf perpustakaan (pustakawan) dengan staf teknologi informasi yang bekerja di perpustakaan. Untuk setiap media publikasi, ditunjuk seorang staf perpustakaan yang bertanggungjawab untuk update isi informasi media yang bersangkutan. Media yang berfungsi sebagai layanan perpustakaan bersifat interaktif (layanan ask librarian), seperti mailing list, website, dan media sosial (instagram, line, facebook). Petugas paling sedikit satu orang pustakawan, yang bertugas menjawab setiap pertanyaan atau permintaan layanan dari para pencari informasi.

Dilihat dari sisi isi (content) media publikasi tersebut selalu aktual dan relevan dengan kebutuhan para pencari informasi. Para pustakawan yang bertanggung jawab sudah terampil untuk menelusur dan menemukan kembali informasi untuk menjawab setiap pertanyaan atau permintaan dari pencari informasi. Dilihat dari aspek performance semua media publikasi sudah tampil cukup baik. Sebagai contoh media video profil Telkom University Open Library dan video testimoni dikemas dengan menarik sehingga dapat memberikan pengetahuan dan membangkitkan citra yang positif tentang perpustakaan pada para penontonnya. Aspek lain yang dinilai positif dari video profil perpustakaan adalah para aktor yang muncul dalam video tersebut, seluruhnya adalah staf perpustakaan. Hal ini menimbulkan perasaan bangga dan merasa dihargai pada mereka sehingga mereka memiliki semangat kerja yang lebih baik dan juga muncul "sense of belonging" pada Telkom University Open Library.

Website Telkom University Open Library dapat dinilai sebagai website yang sudah baik. Mengacu pada penilaian kualitas website berdasarkan kategori Webqual yang meliputi aspek usability, information, service interaction menurut Barnes dan Vidgen (2000), maka website Telkom University Open library dilihat dari aspek usability (kemudahan navigasi, kecocokan disain dan gambaran yang ingin disampaikan) sudah cukup baik. Ketika pencari informasi membuka halaman pertama website, ditemukan fiturfitur yang dapat dipilih untuk mendapatkan informasi yang lebih lengkap. Disainnya juga cukup menarik dan membantu dalam mendapatkan informasi. Sebagai contoh pada halaman beranda, pencari informasi dapat melihat foto cover buku-buku terbaru yang merupakan koleksi perpustakaan. Foto buku tersebut akan bergerak ke arah kiri dalam hitungan beberapa detik, sehingga memudahkan pembaca untuk mendapatkan foto buku lain. Pencari informasi juga dapat langsung melakukan penelusuran dan pemesanan buku. Disain seperti ini sangat memudahkan para pencari informasi untuk mendapatkan buku dalam waktu yang cepat. Media sosial yang digunakan seperti instagram, facebook, dan line-bersifat interaktif dan dinilai sangat efektif untuk melayani permintaan informasi atau menjawab pertanyaan dari mahasiswa. Karena media sosial merupakan media yang sangat tinggi tingkat penggunaanya. Semua publikasi yang telah dibuat diharapkan mampu menginformasikan tentang keberadaan layanan Telkom University Open Library, mampu menciptakan citra yang baik serta membangun kepercayaan pada sivitas akademica Telkom University. 


\section{Penyelenggaraan Event}

Telkom University Open Library menyelenggarakan event khusus yang dilaksanakan pada peristiwa tertentu, seperti event tahunan dalam rangka dies Telkom University dan penerimaan mahasiswa baru. Terdapat pula event rutin berupa open discussion dengan target para mahasiswa. Tema event selalu dikaitkan dengan misi perpustakaan dan isu-isu yang sedang populer di masyarakat. Sebagai contoh tema event tahun 2017 adalah enterpreneur literacy, di mana pada tahun tersebut sedang dicanangkan semangat untuk berwirausaha. Telkom University Open Library memiliki semangat untuk membuka wawasan para mahasiswa melalui literasi kewirausahaan. Selain mahasiswa, dalam event ini masyarakat sekitar juga diundang untuk menjadi peserta pelatihan kewirausahaan pembuatan knitting dan decopage. Hal ini menunjukkan bahwa Telkom University memiliki kepedulian sosial pada pembangunan masyarakat di sekitarnya. Konsep penyelenggaraan event berasal dari staf perpustakaan, sedangkan penyelenggaraannya senantiasa berhubungan dengan pihak eksternal—bantuan dari public relations Telkom University. Penyelenggaraan event ini diharapkan mampu menciptakan citra yang baik pada Telkom University Open Library, baik dari pengguna internal maupun pengguna eksternal, serta membuat Telkom University lebih dikenal oleh masyarakat.

\section{Pembuatan Berita}

Setiap kegiatan yang diselenggarakan di Telkom University Open Library selalu dibuat beritanya. Misalnya pada saat event launching Telkom University Open Library, dibuat berita (press release) dan dikirim melalui email ke media yang menjadi partner, seperti surat kabar Pikiran Rakyat, Koran Sindo, PR FM, dan Detik News.Com. Meskipun setiap berita kegiatan dikirim ke media, namun tidak semua press release dimuat semuanya. Namun, terkait dengan media, pihak perpustakaan bekerjasama dengan public relations Telkom University dan yang membuat press release-nya adalah staf perpustakaan. Pemberitaan penyelenggaraan event di media masa, baik media konvensional maupun media online, diharapkan Telkom Univerity Open Library menjadi lebih dikenal oleh masyarakat luas. Selain itu, berita kegiatan perpustakaan dapat menumbuhkan citra yang baik dan kepercayaan masyarakat bahwa Telkom University sebagai universitas swasta yang sedang berkembang menuju world class university.

\section{Kegiatan Community Involvement}

Kegiatan community involvement yang diselenggarakan oleh Telkom University Open Library dapat dikategorikan sebagai kegiatan corporate social responsibility (CSR). Beberapa kegiatan CSR ini, antara lain:

1) Pemberian sumbangan buku-buku kepada komunitas baca dan taman bacaan masyarakat yang ada di Kabupaten Bandung. Buku-buku yang disumbangkan sebagian besar berasal dari Asia Foundation-Telkom University Open Library menjadi agen Asia Foundation untuk pembagian sumbangan buku-buku kepada masyarakat.

2) Mengundang para murid Taman Kanak-Kanak (TK) untuk berkunjung ke Telkom University Open Library dan memperkenalkan perpustakaan kepada mereka dalam bentuk layanan story telling. Hal ini merupakan kegiatan yang sangat positif, karena masih jarang ada perpustakaan perguruan tinggi yang peduli untuk memperkenalkan 
perpustakaan kepada anak-anak. Kegiatan ini diharapkan mereka menyukai perpustakaan dan gemar membaca sejak usia dini.

3) Mengundang berbagai kalangan untuk berkunjung atau library tour ke Telkom University Open Library. Pesertanya berasal dari berbagai sekolah dan perguruan tinggi. Mereka diperkenalkan sistem pengelolaan perpustakaan modern dan unik, sehingga pengunjung merasa nyaman dengan layanan online perpustakaan.

Kegiatan-kegiatan di atas diharapkan dapat menciptakan citra yang positif dan kepercayaan dari masyarakat eksternal kepada Telkom University.

\section{Pembuatan Identity Media}

Telkom University Open Library hadir dengan identitas sendiri. Universitas ini memiliki logo sendiri yaitu gambar burung hantu $(o w l)$ yang melambangkan pengetahuan. Hal ini menjadi sesuatu yang luar biasa, karena pada umumnya suatu unit kerja yang berada dalam naungan suatu lembaga harus menggunakan logo dari lembaga induknya. Pimpinan universitas telah memberikan izin kepada perpustakaan untuk memiliki logo sendiri. Dalam hal ini, staf perpustakaan mampu meyakinkan para pengambil kebijakan bahwa perpustakaan membutuhkan pengakuan dan dukungan yang besar dari pimpinan. Pimpinan Telkom University juga menyadari bahwa perpustakaan merupakan "jantung" pendidikan sehingga harus selalu dipelihara dan dikembangkan agar mampu menjadi pusat pembelajaran yang berkualitas dan mendukung terciptanya Telkom University yang berkelas dunia. Telkom University Open Library memiliki tagline "to be the centre of knowledge", yang menjadi motivasi seluruh staf perpustakaan agar selalu bekerja secara profesional dan lebih semangat untuk menjadi menjadi pusat ilmu pengetahuan bagi sivitas akademica Telkom University dan pengembangan pendidikan di Indonesia.

Telkom University Open Library juga memiliki baju seragam untuk stafnya. Pada hari Senin, staf perpustakaan memakai seragam yang berwarna putih; pada hari Selasa, seragam berwarna abu-abu; pada hari Rabu, seragam berwarna merah; pada hari Kamis, seragam berwarna hitam. Baju seragam ini menjadi identitas bagi pemakainya yang menunjukkan bahwa ia bagian dari satu kelompok dan akan bangga menjadi bagian kelompok tersebut. Trimo (1992) mengatakan bahwa keberhasilan layanan perpustakaan $80 \%$ ditentukan oleh kinerja staf perpustakaan. Di Telkom University Open Library, keberhasilan telah dicapai dari hasil kinerja staf yang mengelola dan memberikan layanan informasi secara prima untuk membangun citra positif pada Telkom University Open Library. Prinsipnya bahwa identitas yang berupa logo dan baju seragam staf Telkom University Open Library menjadi aspek penting dalam penguatan eksistensi lembaga.

\section{Kegiatan Lobbying}

Kegiatan lobbying atau negosiasi pada pihak internal Telkom University dilakukan oleh kepala Telkom University Open Library. Topik diskusi yang dibahas mengenai pengembangan perpustakaan, dan pelaksanaannya dilakukan dengan kerjasama pihak eksternal. Dalam kegiatan lobbying, staf Telkom University Open Library juga diberi kepercayaan oleh pimpinan perpustakaan, seperti mencari narasumber untuk kegiatan event yang akan diselenggarakan oleh perpustakaan. Dukungan dalam penyelenggaraan event, izin memiliki logo sendiri dan baju seragam untuk staf, merupakan contoh keberhasilan kegiatan lobbying yang telah dilakukan. Kegiatan lobbying yang dilakukan oleh kepala dan 
staf Telkom University Open Library menunjukkan bahwa keberhasilan dalam mendapatkan dukungan dan kepercayaan dari pimpinan Telkom University.

\section{KESIMPULAN}

Telkom University Open Library telah melaksanakan berbagai kegiatan berdasarkan "pencils" of public relations dalam berbagai kegiatan yang berbeda-beda. Berbagai kegiatan dilaksanakan secara terintegrasi dan saling mendukung. Hal tersebut dilakukan untuk peningkatan eksistensi lembaga dan efisiensi kerja. Berbagai kegiatan "pencils" of public relations yang dikonsep oleh staf Telkom University Open Library merupakan bentuk dedikasi, kecerdasan, dan semangat mereka untuk penguatan eksistensi perpustakaan dan lembaga induknya. Sebagai saran penelitian, Telkom University Open Library sebaiknya memiliki tim khusus yang menangani public relations untuk program pengembangan kegiatan perpustakaan dan lembaga yang lebih baik lagi. Selain itu, perlu dilakukan penelitian lanjutan untuk mengetahui dampak dari berbagai kegiatan public relations yang telah dilakukan oleh Telkom University Open Library. 


\section{DAFTAR PUSTAKA}

Ardianto, E. 2011. Handbook of Public Relations: Pengantar Komprehensif. Bandung: Simbiosa Rekatama Media.

Barnes, S. \& Vidgen, R. 2000. WebQual: An Exploration of Website Quality. ECIS 2000 Proceedings. 74.

Elliot de Saez, E. 2002. Marketing Concepts for Libraries and Information Services. London: Facet Publishing.

Harris, Thomas L. 1991. The Marketer's Guide to Public Relations. New York: John Wiley.

Komariah, Neneng \& Rodiah, Saleha. 2017. Implementasi Pencils of Public Relations Dalam Promosi Perpustakaan. Book Chapter. Corporate Public Relations. Bandung: Unpad Press.

Ruslan, Rosady. 2000. Kiat dan Strategi Kampanye Public Relations. Jakarta: Raja Grafindo Persada.

Sulistyo-Basuki. 1991. Pengantar Ilmu Perpustakaan. Jakarta: Gramedia Pustaka Utama Trimo, Soejono. 1992. Pedoman Pelaksanaan Perpustakaan. Bandung: Remaja Rosdakarya.

Usherwood, Bob. 1981. The Visible Library:Practical Public Relations for Public Libraries. London: Library Association.

Wilcox, Dennis L et al. 2000. Public Relations Strategies and Tactics. New York: Longman. Yusup, P.M. 2009. Ilmu Informasi, Komunikasi, dan Kepustakaan. Jakarta: Bumi Aksara.

Zubaedah, Neneng. 2016. Pupuk Kebiasaan Membaca Sejak Dini. Koran Sindo. Hal. 5 